\title{
A neurosurgical approach to traumatic brain injury and post-traumatic hypopituitarism
}

\author{
Chin Lik Tan ${ }^{1,2}$ (D) Peter J. Hutchinson ${ }^{2}$
}

Published online: 27 November 2018

(c) The Author(s) 2018

\begin{abstract}
Purpose Traumatic brain injury (TBI) is a common cause of mortality and major disability worldwide. The initial management often depends on the severity of the injury. Pituitary dysfunction can develop as a sequela of TBI, and can have longterm, debilitating impact on the patients. Early identification and prompt intervention of post-traumatic hypopituitarism (PTHP) is essential to prevent or minimize the adverse consequences of this condition. We hereby provide an overview of the current management of TBI from a neurosurgical standpoint. We then review the pathophysiology and risk factors of developing PTHP, as well as our recommendations for its management.

Methods A review of current literature on TBI and PTHP, including primary research articles, reviews and clinical guidelines. Results The current neurosurgical approach to the management of TBI is presented, followed by the pathophysiology and risk factors of PTHP, as well as our recommendations for its management.

Conclusions Post-traumatic hypopitutiarism is a serious and potentially debilitating condition that is likely under-recognised and under-diagnosed. From a neurosurgical perspective, we advocate a pragmatic approach, i.e. screening those considered at high risk of developing PTHP based on clinical features and biochemical/endocrinological testings; and referring them to a specialist endocrinologist for further management as indicated.
\end{abstract}

Keywords Traumatic brain injury $\cdot$ Hypopituitarism $\cdot$ Neurosurgery

\section{Traumatic brain injury}

Traumatic brain injury (TBI) is a serious, common and potentially devastating condition which is a major cause of mortality and major disability in the developed and developing world alike. Worldwide, it is estimated that approximately 69 million people suffer from TBI each year, with Southeast Asia and Western Pacific regions experiencing the highest burden of disease [1]. In the developed world, North America and Europe have an estimated incidence of $1,299 / 100,000$ and 1,012/100,000 per year, respectively [1].

Peter J. Hutchinson

pjah2@cam.ac.uk

Chin Lik Tan

chinlik.tan@cantab.net

1 Division of Neurosurgery, National University Hospital, 5 Lower Kent Ridge Road, Singapore 119074, Singapore

2 Division of Neurosurgery, Department of Clinical Neurosciences, University of Cambridge, Cambridge Biomedical Campus, Box 167, CB2 0QQ Cambridge, UK
The leading causes of TBI are falls, road traffic accidents and assault. Males are twice as likely to suffer from TBI as females. With an increasingly aging population, the incidence of TBI among the elderly is also increasing, with falls being the major contributor. In the United States, more than 80,000 attendances to the Emergency Department per year were made by patients aged 65 or older, three-quarter of whom require hospitalization [2].

TBI can be classified according to the post-resuscitation Glasgow Coma Scale (GCS) score, into mild (GCS 13-15), moderate (GCS 9-12) and severe (GCS 3-8). Patients who sustained severe TBI often require hospitalization ranging from weeks to months. Many of these patients end up in coma or becoming fully dependent on others for round-theclock care. Even among those with mild or moderate TBI, long-term sequelae may entail, resulting in chronic headache, dizziness, attention or cognitive deficits, memory problems and behavioural issues. Some of these symptoms may be identified as part of post-concussion syndrome (PCS), but others may also suffer from pituitary dysfunction or chronic traumatic encephalopathy. These complications, if untreated, 
may lead to impaired functional status, loss of productivity and poor quality of life.

\section{Management of traumatic brain injury}

Following a traumatic insult, the brain suffers an immediate injury as a result of the mechanical impact. This is termed primary injury and is irreversible. However, this may trigger a range of physical, biochemical and cerebrovascular changes that can result in further injuries, i.e. secondary injury to the brain. This includes cerebral ischaemia, oedema, disturbed metabolism and excitotoxicity, and are reversible if managed correctly and promptly. However, if untreated, they can have long term deleterious outcome on the patient. The main goal of acute neurosurgical care of TBI patients is the prevention of secondary injuries.

The initial management of TBI patients depends primarily on the severity of the injury as assessed by the GCS score, taking into consideration other factors such as associated injuries (in a polytrauma setting) and pre-morbid status.

Severe TBI patients are managed according to the Brain Trauma Foundation Guidelines for the Management of Severe Traumatic Brain Injury [3]. The primary aim of management of severe TBI patients is the prevention and treatment of secondary brain injury, in order to preserve maximal amount of normally-functioning brain tissue. Patients with severe TBI should be transferred to a neurosurgical centre with expertise in neurotrauma care. This enables management in an intensive care setting, with intensive monitoring and correction of basic physiological parameters (e.g. blood pressure, pulse rate, oxygen saturation, temperature etc.), metabolic derangements (e.g. electrolytes, glucose, nutritional status etc.), neurological status (GCS score, pupil size and reactivity, focal neurological deficits etc.) and intracranial pressure (ICP). The most basic target is to regulate/ lower the ICP and optimize cerebral perfusion pressure (CPP). This is initially done using medical measures, such as sedation, osmotherapy (mannitol or hypertonic saline), hyperventilation, maintenance of optimal blood pressure, oxygenation and temperature, as well as prevention and treatment of seizures and infection. An external ventricular drain (EVD) may also be inserted into the ventricular system to drain the cerebrospinal fluid (CSF) to lower the ICP. However, if the ICP remains refractory to medical treatment, surgery in the form of decompressive craniectomy may be indicated.

Patients who have sustained mild TBI are managed quite differently. Upon attendance to the Emergency Department, a set of criteria based on patient's clinical conditions may be used to guide the necessity for performing a CT head scan [4]. Depending on the patient's GCS score, neurological status, CT scan findings, as well as other symptoms or signs and co-morbidities, the patient may either be admitted for further monitoring or discharged from the Emergency Department. Those admitted will be monitored for GCS score and focal neurological deficits; if patients remain stable during this period of monitoring, they will be typically discharged after 24-48 $\mathrm{h}$.

\section{Post-traumatic hypopituitarism}

Post-traumatic hypopituitarism (PTHP) was first described nearly a century ago in 1918 [5]. However, it did not gain much attention until the recent two decades or so. It is now accepted that PTHP is a poorly-recognised and under-diagnosed sequela following TBI. Nevertheless the true prevalence of PTHP remains a matter of controversy, with studies reporting widely disparate figures, to as high as almost $70 \%$. These inconsistencies may be attributed to the differences in inclusion/exclusion criteria, tests employed (e.g. dynamic vs static tests), timings of the testing (acute vs chronic phases) and threshold for diagnosis [6, 7]. Our recent review article includes a compilation of studies looking at the prevalence of abnormal endocrine tests in patients with TBI [8].

Pituitary dysfunction can lead to physical, psychological and cognitive complications. Acute pituitary dysfunction can result in adrenal insufficiency or diabetes insipidus (DI) which can cause haemodynamic instability and derangements in fluid balance. In the longer term, PTHP patients could suffer from attention and cognitive deficits, impaired quality of life and poor rehabilitation outcome [9-11]. Many neuropsychiatric manifestations following TBI including depression, anxiety, loss of emotional well-being have also been linked to PTHP, and have been documented up to $30 \%$ of patients [12]. Hence it is crucial to identify PTHP, both in the acute as well as chronic phases, in order to institute appropriate and timely treatment.

\section{Pathophsiology of post-traumatic hypopituitarism}

Various theories have been proposed as possible pathophysiological mechanisms underlying PTHP. The most widelyaccepted theory is that of an ischaemic insult to the pituitary gland $[13,14]$. TBI can cause direct trauma to the pituitary gland $[15,16]$, transection/disruption of the pituitary stalk [17-19] or direct damage to the hypophyseal portal veins $[17,20]$. Additional insults in the form of hypotension, hypoxia and brain swelling often seen in TBI may further exacerbate the injury, resulting in pituitary ischaemia and infarction [21].

Another possible mechanism is a direct mechanical impact to the pituitary gland. Being located in the sella 
turcica, the pituitary gland is particularly susceptible to injuries that involve basal skull fractures. It is believed that the more prevalent $\mathrm{GH}$ and gonadotrophin deficiencies in PTHP are due to the more laterally-located somatotrophs and gonadotrophs $[22,23]$. Shearing of white matter tracts connecting the pituitary gland may also be injured by acceleration/deceleration forces exerted during TBI.

The role of autoimmunity in the development of PTHP has also been studied. TBI patients were found to have higher levels of anti-pituitary antibodies (APAs) and antihypothalamic antibodies (AHAs) at 3 and 5 years postinjury, compared to controls [24, 25]. High levels of APAs and AHAs were also detected in boxers, who frequently sustained chronic, repetitive insults to the brain. Higher levels of AHAs among boxers were found to be associated with higher prevalence of PTHP (46.2\%) compared to controls $(10.4 \%)[24,26]$.

Post-mortem studies also helped unveil the pathological process that may underlie PTHP. Features including capsular haemorrhage around the pituitary (59\%), posterior lobe haemorrhage (31\%), anterior lobe necrosis $(22 \%)$ and stalk necrosis $(3 \%)[20,27]$. A more recent study in fatal closed TBI patients found high prevalence of pituitary stalk rupture and pituitary gland haemorrhage (43.3\%), and that this was associated with the presence of subdural haemorrhage [28]. Ischaemic/haemorrhagic lesions in the hypothalamus have also been detected in approximately $42 \%$ of patients, suggesting a possibility of hypothalamic involvement in PTHP [15].

The advent of imaging technology also allowed closer inspection of radiological changes in and around the pituitary gland following TBI. Maiya et al. studied the MRI scans of 41 moderate-severe TBI patients and found evidence of pituitary enlargement in the acute phase ( $<7$ days). Other focal lesions were also detected in $30 \%$ of the patients, and included haemorrhage/haemorrhagic infarction, a swollen gland with bulging superior margin, heterogeneous signal in the anterior lobe, and partial transection of the infundibular stalk [19]. On the other hand, a study on longer-term cohort of TBI patients (mean 17.4 years after trauma), revealed a loss of pituitary volume or an empty sella, abnormal enhancement, perfusion deficits and/or lack of the posterior pituitary signal to be the main imaging findings [29]. Studying a cohort of soldiers who sustained blast TBI, Baxter et al. discovered that those who had pituitary dysfunction displayed greater white matter tract damage as assessed by diffusion tensor imaging [30]. The prevalence of skull/facial fractures was also higher among the soldiers with pituitary dysfunction (50\%) compared to those without (0\%) [30].

\section{Risks factors of post-traumatic hypopituitarism}

It is still unknown which group of patients are more likely to develop pituitary dysfunction following TBI. Various putative risks factors, covering clinical, radiological and genetic aspects, have been suggested from earlier studies.

A number of studies have identified the initial GCS score as a predictor for developing PTHP [31-35]. A meta-analysis of 14 studies found that patients with severe TBI $($ GCS $<9)$ had the highest rate of developing PTHP $(35.5 \%)$. However, the authors also found that moderate TBI patients (GCS 9-12) had a lower rate of PTHP (10.9\%) compared to mild TBI patients (GCS 13-15) (16.8\%) [29]. However, findings from several other studies appeared to contradict this, suggesting instead that there exists no causal relationship between GCS score and PTHP [36-40].

Several groups also identified imaging findings that may be predictive of development of PTHP. This include findings from CT scan including diffuse brain swelling [31], basal skull fractures and diffuse axonal injury [39]. However, two studies did not find a correlation between PTHP and imaging findings of intracranial haematoma or diffuse axonal injury [32, 37].

Other factors associated with development of PTHP include old age [39], raised intracranial pressure [41, 42], hypotension and hypoxia [31], and prolonged ICU stay. Possession of apolipoprotein E3/E3 genotype was found to be associated with a lower risk of PTHP [43].

Mechanism of injury may also be associated with PTHP. Blast TBI has been found to confer higher risk of PTHP, based on studies on military personnel returning from warzones [30, 44]. Baxter et al. identified that patients who suffered moderate-severe blast TBI had a higher risk of developing PTHP (32.0\%) compared to those with nonblast TBI (2.6\%) [30]. Undurti et al., meanwhile, found high prevalence (31\%) of PTHP among army veterans with prior blast mild TBI, which was associated with increased post-concussive symptoms [44].

\section{Recommendations for screening and management of post-traumatic hypopituitarism}

A number of authors have put forward various recommendations for the management of PTHP [7, 45, 46]. While the details may differ, the general concepts appear similar.

On behalf of the British Neurotrauma Group, we recently published a set of guidance on the screening and 
management of pituitary dysfunction following TBI in adults [8]. The aim of the publication was two-fold: to provide guidance to clinicians (including neurosurgeons, intensive care specialists, surgeons and physicians) on who, when and how to screen for and manage pituitary dysfunction following TBI; and to provide a framework for future research in this area to further refine and update the recommendations as and when new evidence emerge [8].

\section{The acute phase in hospital}

Various physiological changes occur in the acute phase following intercurrent illnesses, including TBI. This may affect levels of hormones detected, resulting in false positives. This makes interpretation of endocrine test results extremely challenging and potentially unreliable. Hence, in contrast to suggestions from other authors [7, 46], we do not recommend routine testing of endocrine function or assessment of plasma/serum cortisol level in the acute phase following TBI. However, if a patient displays signs of cortisol insufficiency (e.g. refractory hypotension, hypoglycaemia, hyponatraemia), cranial DI (e.g. hypernatraemia, hypotonic polyuria) or syndrome of inappropriate antidiuretic hormone secretion(SIADH) (e.g. euvolaemic hyponatraemia), appropriate investigations should be carried out and hormone replacement be given immediately [8].

\section{The post-discharge and chronic phase}

Many authors recommend screening for patients who had moderate-severe TBI at 3-6 months to detect PTHP, using a combination of basal (non-stimulated), and where appropriate, dynamic tests $[7,47-50]$. We recommend that all patients who are admitted for $48 \mathrm{~h}$ or more for TBI undergo screening for PTHP at 3-6 months. This should include renal function tests, thyroid function tests, cotisol level and sex hormone levels. If abnormality is detected, they should be referred to an endocrinologist to have a full assessment, including a dynamic testing for growth hormone deficiency (GHD) [8]. Patients who are not admitted, or who are admitted for less than $48 \mathrm{~h}$ should also undergo screening tests if they have on-going symptoms consistent with pituitary dysfunction. GHD is commonly transient, and does not require testing within 12 months. However, TBI patients who have persistent symptoms beyond 12 months should undergo testing for GHD and other pituitary abnormalities [8].

It must be borne in mind that many mild TBI patients may not be placed under the care of neurosurgeons. This is particularly true for elderly patients admitted for falls, who are often cared for by physicians throughout their hospital stay. Hence physicians who are frequently involved in the care of TBI patients (e.g. acute care physicians, geriatricians) should also be aware of the possibility of PTHP and follow these patients up accordingly.

\section{Conclusions}

Post-traumatic hypopitutiarism is a serious and potentially debilitating condition that may afflict sufferers of TBI. While its true prevalence remains to be determined, it is likely that this condition is under-recognized and under-diagnosed. More concerted efforts are required to understand the epidemiology, pathophysiology, and risk factors in order to develop better screening tools and therapeutic strategies to improve the management of these patients.

Our current approach to PTHP can be considered a pragmatic one. The incidence of TBI (from mild to severe) is very high and it is impossible to screen everyone for pituitary dysfunction. Hence our strategy is to screen those considered at high risk of developing PTHP based on clinical features and biochemical/endocrinological testings; and when an abnormality is detected, to refer them to a specialist endocrinologist for further management. Nevertheless, we view this approach as a work in-progress, and should be updated and improved upon as and when new evidence becomes available.

Acknowledgements Peter J. Hutchinson is supported by the National Institute for Health Research (NIHR) Research Professorship, the NIHR Cambridge Biomedical Research Centre, and the NIHR Global Health Research Group on Neurotrauma.

Conflict of interest The authors declare that they have no conflict of interest.

Open Access This article is distributed under the terms of the Creative Commons Attribution 4.0 International License (http://creativeco mmons.org/licenses/by/4.0/), which permits unrestricted use, distribution, and reproduction in any medium, provided you give appropriate credit to the original author(s) and the source, provide a link to the Creative Commons license, and indicate if changes were made.

\section{References}

1. Dewan MC, Rattani A, Gupta S, Baticulon RE, Hung YC, Punchak M, Agrawal A, Adeleye AO, Shrime MG, Rubiano AM, Rosenfeld JV, Park KB (2018) Estimating the global incidence of traumatic brain injury. J Neurosurg. https://doi.org/10.3171/2017.10.JNS17 352

2. Taylor CA, Bell JM, Breiding MJ, Xu L (2017) Traumatic brain injury-related emergency department visits, hospitalizations, and deaths-United States, 2007 and 2013. MMWR Surveill Summ 66(9):1-16

3. Carney N, Totten AM, O'Reilly C, Ullman JS, Hawryluk GW, Bell MJ, Bratton SL, Chesnut R, Harris OA, Kissoon N, Rubiano AM, Shutter L, Tasker RC, Vavilala MS, Wilberger J, Wright 
DW, Ghajar J (2017) Guidelines for the management of severe traumatic brain injury, fourth edition. Neurosurgery 80(1):6-15

4. National Institute for Health and Care Excellence (NICE) Clinical Guideline 176 (CG176) (2018). Head injury: assessment and early management. https://www.nice.org.uk/guidance/cg176. Accessed 21 Sept 2018

5. Cyran E (1918) Hypophysenschädigung durch schädelbasisfraktur. Dtsch Med Wochenschr 44(45):1261

6. Kokshoorn NE, Wassenaar MJ, Biermasz NR, Roelfsema F, Smit JW, Romijn JA, Pereira AM (2010) Hypopituitarism following traumatic brain injury: prevalence is affected by the use of different dynamic tests and different normal values. Eur J Endocrinol 162(1):11-18

7. Glynn N, Agha A (2013) Which patient requires neuroendocrine assessment following traumatic brain injury, when and how? Clin Endocrinol (Oxf) 78(1):17-20

8. Tan CL, Alavi SA, Baldeweg SE, Belli A, Carson A, Feeney C, Goldstone AP, Greenwood R, Menon DK, Simpson HL, Toogood AA, Gurnell M, Hutchinson PJ (2017) The screening and management of pituitary dysfunction following traumatic brain injury in adults: British Neurotrauma Group guidance. J Neurol Neurosurg Psychiatry 88(11):971-981

9. Popovic V, Pekic S, Pavlovic D, Maric N, Jasovic-Gasic M, Djurovic B, Medic Stojanoska M, Zivkovic V, Stojanovic M, Doknic M, Milic N, Djurovic M, Dieguez C, Casanueva FF (2004) Hypopituitarism as a consequence of traumatic brain injury (TBI and its possible relation with cognitive disabilities and mental distress. $\mathrm{J}$ Endocrinol Invest 27(11):1048-1054

10. Kelly DF, McArthur DL, Levin H, Swimmer S, Dusick JR, Cohan P, Wang C, Swerdloff R (2006) Neurobehavioral and quality of life changes associated with growth hormone insufficiency after complicated mild, moderate, or severe traumatic brain injury. $\mathrm{J}$ Neurotrauma 23(6):928-942

11. Bondanelli M, Ambrosio MR, Cavazzini L, Bertocchi A, Zatelli MC, Carli A, Valle D, Basaglia N, Uberti EC (2007) Anterior pituitary function may predict functional and cognitive outcome in patients with traumatic brain injury undergoing rehabilitation. J Neurotrauma 24(11):1687-1697

12. Molaie AM, Maguire J (2018) Neuroendocrine Abnormalities Following Traumatic Brain Injury: An Important Contributor to Neuropsychiatric Sequelae. Front Endocrinol (Lausanne) 9:176

13. Dusick JR, Wang C, Cohan P, Swerdloff R, Kelly DF (2012) Pathophysiology of hypopituitarism in the setting of brain injury. Pituitary 15(1):2-9

14. Fernandez-Rodriguez E, Bernabeu I, Castro AI, Kelestimur F, Casanueva FF (2011) Hypopituitarism following traumatic brain injury: determining factors for diagnosis. Front Endocrinol (Lausanne) 2:25

15. Crompton MR (1971) Hypothalamic lesions following closed head injury. Brain 94:165-172

16. Salehi F, Kovacs K, Scheithauer BW, Pfeifer EA, Cusimano M (2007) Histologic study of the human pituitary gland in acute traumatic brain injury. Brain Inj 21(6):651-656

17. Daniel PM, Prichard MM, Treip CS (1959) Traumatic infarction of the anterior lobe of the pituitary gland. Lancet 2:927-931

18. Khan K, Saeed S, Ramcharan A, Gray S (2018) A case series of closed head trauma with pituitary stalk disruption resulting in hypopituitarism. Int J Surg Case Rep 43:69-71

19. Maiya B, Newcombe V, Nortje J, Bradley P, Bernard F, Chatfield D, Outtrim J, Hutchinson P, Matta B, Antoun N, Menon D (2008) Magnetic resonance imaging changes in the pituitary gland following acute traumatic brain injury. Intensive Care Med 34(3):445-468

20. Kornblum RN, Fisher RS (1969) Pituitary lesions in craniocerebral injuries. Arch Pathol 88:242-248
21. Wachter D, Gündling K, Oertel MF, Stracke H, Böker DK (2009) Pituitary insufficiency after traumatic brain injury. J Clin Neurosci 16(2):202-208

22. Popovic V (2005) GH deficiency as the most common pituitary defect after TBI: clinical implications. Pituitary 8:239-243

23. Benvenga S, Campenní A, Ruggeri RM, Trimarchi F (2000) Clinical review 113: Hypopituitarism secondary to head trauma. J Clin Endocrinol Metab 85(4):1353-1361

24. Tanriverdi F, De Bellis A, Bizzarro A, Sinisi AA, Bellastella G, Pane E, Bellastella A, Unluhizarci K, Selcuklu A, Casanueva FF, Kelestimur F (2008) Antipituitary antibodies after traumatic brain injury: is head trauma-induced pituitary dysfunction associated with autoimmunity? Eur J Endocrinol 159(1):7-13

25. Tanriverdi F, De Bellis A, Ulutabanca H, Bizzarro A, Sinisi AA, Bellastella G, Amoresano Paglionico V, Dalla Mora L, Selcuklu A, Unluhizarci K, Casanueva FF, Kelestimur F (2013) A five year prospective investigation of anterior pituitary function after traumatic brain injury: is hypopituitarism long-term after head trauma associated with autoimmunity? J Neurotrauma 30(16):1426-1433

26. Tanriverdi F, De Bellis A, Battaglia M, Bellastella G, Bizzarro A, Sinisi AA, Bellastella A, Unluhizarci K, Selcuklu A, Casanueva FF, Kelestimur F (2010) Investigation of antihypothalamus and antipituitary antibodies in amateur boxers: is chronic repetitive head trauma-induced pituitary dysfunction associated with autoimmunity? Eur J Endocrinol 162(5):861-867

27. Ceballos R (1966) Pituitary changes in head trauma (analysis of 102 consecutive cases of head injury). Ala J Med Sci 3(2):185-198

28. Idowu OE, Obafunwa JO, Soyemi SO (2017) Pituitary gland trauma in fatal nonsurgical closed traumatic brain injury. Brain Inj 31(3):359-362

29. Schneider HJ, Sämann PG, Schneider M, Croce CG, Corneli G, Sievers C, Ghigo E, Stalla GK, Aimaretti G (2007) Pituitary imaging abnormalities in patients with and without hypopituitarism after traumatic brain injury. J Endocrinol Invest 30(4):RC9-RC12

30. Baxter D, Sharp DJ, Feeney C, Papadopoulou D, Ham TE, Jilka S, Hellyer PJ, Patel MC, Bennett AN, Mistlin A, McGilloway E, Midwinter M, Goldstone AP (2013) Pituitary dysfunction after blast traumatic brain injury: The UK BIOSAP study. Ann Neurol 74(4):527-536

31. Kelly DF, Gonzalo IT, Cohan P, Berman N, Swerdloff R, Wang C (2000) Hypopituitarism following traumatic brain injury and aneurysmal subarachnoid hemorrhage: a preliminary report. J Neurosurg 93(5):743-752

32. Bondanelli M, De Marinis L, Ambrosio MR, Monesi M, Valle D, Zatelli MC, Fusco A, Bianchi A, Farneti M, degli Uberti EC (2004) Occurrence of pituitary dysfunction following traumatic brain injury. J Neurotrauma 21(6):685-696

33. Klose M, Juul A, Poulsgaard L, Kosteljanetz M, Brennum J, FeldtRasmussen U (2007) Prevalence and predictive factors of posttraumatic hypopituitarism. Clin Endocrinol (Oxf) 67(2):193-201

34. Klose M, Juul A, Struck J, Morgenthaler NG, Kosteljanetz M, Feldt-Rasmussen U (2007) Acute and long-term pituitary insufficiency in traumatic brain injury: a prospective single-centre study. Clin Endocrinol (Oxf) 67(4):598-606

35. Hadjizacharia P, Beale EO, Inaba K, Chan LS, Demetriades D (2008) Acute diabetes insipidus in severe head injury: a prospective study. J Am Coll Surg 207(4):477-484

36. Lieberman SA, Oberoi AL, Gilkison CR, Masel BE, Urban RJ (2001) Prevalence of neuroendocrine dysfunction in patients recovering from traumatic brain injury. J Clin Endocrinol Metab 86(6):2752-2756

37. Agha A, Rogers B, Sherlock M, O'Kelly P, Tormey W, Phillips J, Thompson CJ (2004) Anterior pituitary dysfunction in 
survivors of traumatic brain injury. J Clin Endocrinol Metab 89(10):4929-4936

38. Aimaretti G, Ambrosio MR, Di Somma C, Gasperi M, Cannavò S, Scaroni C, Fusco A, Del Monte P, De Menis E, Faustini-Fustini M, Grimaldi F, Logoluso F, Razzore P, Rovere S, Benvenga S, Degli Uberti EC, De Marinis L, Lombardi G, Mantero F, Martino E, Giordano G, Ghigo E (2005) Residual pituitary function after brain injury-induced hypopituitarism: a prospective 12-month study. J Clin Endocrinol Metab 90(11):6085-6092

39. Schneider M, Schneider HJ, Yassouridis A, Saller B, von Rosen F, Stalla GK (2008) Predictors of anterior pituitary insufficiency after traumatic brain injury. Clin Endocrinol (Oxf) 68(2):206-212

40. Kozlowski Moreau O, Yollin E, Merlen E, Daveluy W, Rousseaux M (2012) Lasting pituitary hormone deficiency after traumatic brain injury. J Neurotrauma 29(1):81-89

41. Klose M, Watt T, Brennum J, Feldt-Rasmussen U (2007) Posttraumatic hypopituitarism is associated with an unfavorable body composition and lipid profile, and decreased quality of life 12 months after injury. J Clin Endocrinol Metab 92(10):3861-3868

42. Klose M, Stochholm K, Janukonyté J, Lehman Christensen L, Frystyk J, Andersen M, Laurberg P, Christiansen JS, Feldt-Rasmussen U (2014) Prevalence of post-traumatic growth hormone deficiency is highly dependent on the diagnostic set-up: results from The Danish National Study on Posttraumatic Hypopituitarism. J Clin Endocrinol Metab 99(1):101-110

43. Tanriverdi F, Taheri S, Ulutabanca H, Caglayan AO, Ozkul Y, Dundar M, Selcuklu A, Unluhizarci K, Casanueva FF, Kelestimur F (2008) Apolipoprotein E3/E3 genotype decreases the risk of pituitary dysfunction after traumatic brain injury due to various causes: preliminary data. J Neurotrauma 25(9):1071-1077
44. Undurti A, Colasurdo EA, Sikkema CL, Schultz JS, Peskind ER, Pagulayan KF, Wilkinson CW (2018) Chronic hypopituitarism associated with increased postconcussive symptoms is prevalent after blast-induced mild traumatic brain injury. Front Neurol 19:9:72

45. Quinn M, Agha A (2018) Post-traumatic hypopituitarism-who should be screened, when, and how? Front Endocrinol (Lausanne) 9:8

46. Tanriverdi F, Unluhizarci K, Kelestimur F (2010) Pituitary function in subjects with mild traumatic brain injury: a review of literature and proposal of a screening strategy. Pituitary 13:146-153

47. Schneider HJ, Kreitschmann-Andermahr I, Ghigo E, Stalla GK, Agha A (2007) Hypothalamopituitary dysfunction following traumatic brain injury and aneurysmal subarachnoid hemorrhage: a systematic review. JAMA 298(12):1429-1438

48. Tritos NA, Yuen KC, Kelly DF, AACE Neuroendocrine and Pituitary Scientific Committee (2015) American Association of Clinical Endocrinologists and American College of Endocrinology Disease State Clinical Review: a neuroendocrine approach to patients with traumatic brain injury. Endocr Pract 21:823-831

49. Ghigo E, Masel B, Aimaretti G, Léon-Carrión J, Casanueva FF, Dominguez-Morales MR, Elovic E, Perrone K, Stalla G, Thompson C, Urban R (2005) Consensus guidelines on screening for hypopituitarism following traumatic brain injury. Brain Inj 19:711-724

50. Sesmilo G, Halperin I, Puig-Domingo M (2007) Endocrine evaluation of patients after brain injury: what else is needed to define specific clinical recommendations? Hormones (Athens) 6:132-137 